\title{
Parasite surveillance and novel use of anthelmintics in cattle
}

\author{
Johan Höglund \\ From Parasite infections of domestic animals in the Nordic countries - emerging threats and challenges. \\ The 22nd Symposium of the Nordic Committee for Veterinary Scientific Cooperation (NKVet) \\ Helsinki, Finland. 7-9 September 2008
}

\section{Background}

Cattle are economically the most important livestock for farmers in Sweden. However, both dairy and beef production has been subjected to considerable structural change over recent decades. Currently, there are approximately 1.5 million cattle, including $\approx 370000$ dairy cows producing milk worth $1 \mathrm{~m} €[1]$. The trend is that the numbers of dairy cows are decreasing slowly, while beef cows are somewhat increasing. At the same time as the productivity has been intensified since the 1950 's in the cattle sector, herd size has increased and the number of production units, especially the number of dairy farms, have been dramatically reduced. In contrast, the numbers of organic farms are steadily increasing. The goal of the Swedish government is to increase the Swedish organic production of agricultural commodities to $20 \%$ within a three-year period.

According to the Swedish animal welfare regulations, both conventional and organic cattle must have access to pasture for a period of 2-3 months per year [2]. The grazing season normally occurs between early May and October. As pasture-borne parasites are ubiquitous wherever animals are grazing, they remain one of the most important productivity constraints in Swedish cattle production. These parasites have in common that they often exhibit simple direct life cycles with infective stages transmitted on pasture by the faecal-oral route. The most important pasture-borne parasites of grazing cattle in Sweden are the gastrointestinal (GI) nematodes Ostertagia ostertagi and Cooperia oncophora. To a lesser degree, the lungworm Dictyocaulus viviparus, and also the coccidian Eimeria alabamensis, are important

Department of Biomedical Sciences and Veterinary Public Health, Div. of Parasitology and Virology (SWEPAR), Swedish University of Agricultural Sciences (SLU), SE-751 80 Uppsala, Sweden pathogens. Furthermore, in wet areas the liver fluke Fasciola hepatica, with a complex life cycle, sometimes cause problems.

The importance of GI-nematodes and lungworms on the productivity in first-season grazing (FSG) cattle has been demonstrated in a range of independent grazing trials conducted at SWEPAR over the last decade [3-8]. According to the results, the weight-gain penalties in unprotected set stocked FSG animals were on an average in the range of 20 to $65 \mathrm{~kg}$, compared to simultaneously grazed calves but that were fully protected from parasites by the use of effective anthelmintics. Combined, these trials demonstrate the importance of nematode parasites on animal productivity under Swedish climatic and management conditions. They also show that good levels of nematode control can be achieved through the correct use of anthelmintics. However, at the same time there are concerns that over-dependence on 'chemical' control may lead to long-term difficulties. This occurs partly through development of anthelmintic resistance, but also because these substances are not widely accepted among consumers. Routine prophylactic use of anthelmintics is not accepted in organic livestock farming [9]. However, "blanket" treatment of the whole grazing group or herd is accepted, even on organic farms, in response to a worm problem after it has been diagnosed.

Although the results from our grazing trials also have shown that good levels of parasite control can be achieved without anthelmintics, some of the alternative non-chemical parasite control approaches that we have tested are impractical. For example, when it comes to the use of natural pasturelands there are situations where high grazing pressure must be maintained in order to maintain a profile necessary for the generation of subsidies. Young and adult stock on Swedish dairy 
farms are also often grazed on dedicated pastures, which omits the opportunities for mixed grazing between different age groups. There are many examples of organic cattle farmers who have obtained exemptions from the organic guidelines because their animals have suffered from nematode parasites.

In this contribution, the focus is on diagnostic methods that can be used for individual and/or herd parasite monitoring in parasite surveillance programmes. I will also briefly discuss future ways to refine the use of anthelmintics through targeted selective treatments (TSTs). The latter is a sustainable deworming method that can be applied in both conventional and organic cattle production. Finally, some results from an ongoing EU project (PARASOL, http://www.parasol-project.org/) will be presented.

\section{Sustainable use of anthelmintics}

For the foreseeable future it can be assumed that anthelmintics will constitute the cornerstone of most parasite control programmes, irrespective of whether they are used alone or in an integrated programme. However, to preserve the efficacy and to reach a wider level of acceptance, including organic producers, it is unavoidable to refine the ways in which anthelmintics are used. One possibility is to replace current treatment regimes with TSTs. Today in Sweden, anthelmintics are either administered at strategic times to all first grazing season cattle at risk (e.g. against GI-nematodes), or given as metaphylactic mass treatments following the appearance of clinical signs in some animals in a grazing group (e.g. against lungworm). In order to create low input and sustainable programs for nematode control, TST strategies must not only be further developed but also validated under practical farming conditions. The long-term aim with TST is to minimise the number of whole herd/flock anthelmintic treatments by directing treatments towards only those animals/herds that are likely to suffer from disease and production loss. Overall, this will reduce the opportunities for any associated environmental and health risks, while maintaining agricultural productivity.

The concept of TST is simple and easy to accept, especially in situations where animals with a high worm burden are easily identified, for example by showing clinical signs such as coughing, diarrhoea, emaciation or reduced productivity. However, it is well recognised that the greatest losses associated with pasture-borne nematode parasites in grazing livestock are sub-clinical. Economic assessments have also shown that the financial costs associated with sub-clinical parasitism are enormous [10]. It can also be argued that it is suboptimal and often too late to treat with an anthelmintic when clinical signs have already been observed, as animals showing signs of disease are most likely to propagate infection. Essential for the TST approach is that there be access to good and reliable indicators, and identification of treatment thresholds.

\section{Potential TST indicators}

There are many potential TST indicators, which can be grouped according to whether they are parasitological, pathophysiological or performance factors. Those indicators based on traditional parasitological techniques, such as faecal egg counts (FEC), and in particular pasture larval counts and tracer tests, are generally impractical, as they are either extremely laborious and/or non-informative when required [11]. Accordingly, it can be expected that they will not be feasible as indicators for the purpose of monitoring cattle health. One exception might be the recently developed FECPAC technology (http:// www.fecpak.com/), which might serve its purpose. However, this technology must first be carefully tested and evaluated in field before it can be recommended as a routine measure.

Among the serological tests there are several promising candidates. Recently it has been demonstrated that both serum pepsinogen concentrations (SPC) and antibody levels at housing provide very useful information about previous exposure to nematode parasites. SPC is a pathophysiological indicator measuring the damage caused to the abomasal mucosa, and it has been shown to correlate with the occurrence of parasitic gastroenteritis, both in naturally infected animals [12] and in young cattle experimentally infected with different levels of $O$. ostertagi [13]. However, the use of SPC is restricted, as it can only be used to predict exposure of FSG animals to this particular parasite.

Another option is to detect specific IgG antibody serum levels with immunological methods using ELISA. Currently there are several in-house ELISAs for the detection of Ostertagia and Cooperia spp. Of particular interest is the ELISA using crude proteins from whole worm extracts of O. ostertagi, as it has been demonstrated that this ELISA not only reflects parasite exposure [13] but also reflects the damage caused in terms of reduced production traits and milk yield $[14,15]$. Interestingly, this test was recently evaluated to measure antibody levels against this abomasal parasite in bulk tank milk [16]. To what level parasite exposure in cows is correlated with the situation found in heifers and calves on the same farm remains obscure. Although this aspect is currently being investigated within PARASOL, it is certainly a topic that requires more attention in the future. Milk is commonly tested for a range of infectious diseases, and results from the Ostertagia test could then easily be incorporated into existing herd health surveillance programmes. 
If not tested beforehand, the suitability of using milk ELISAs against other important parasites should also be explored. It is important to realise that the costs of sampling and testing must be minimised before a herd health monitoring programme can reach more general acceptance among representatives in authorities, livestock organisations and, not least, the farming community.

\section{Ongoing research}

Since 2006 SWEPAR has been actively involved in the PARASOL project. This is an ongoing STREP activity coordinated by Professor Joseph Vercruysse, Ghent University, Belgium, and aimed at helminth control in grazing ruminants. The work in Sweden has mainly been focussed on cattle, with the the specific aims: (1) to compare the pepsinogen and antibody levels against $O$. ostertagi in FSG animals at housing, and (2) to predict the situation in the FSG stock by investigating the antibody levels in bulk tank milk from the same herds.

A total of 44 dairy farms in south-central Sweden were randomly selected in 2005. From each farm bulk tank milk was sampled along with serum from 10 FSG at the time of housing. The same farms were also approached to participate the following year, and in 200636 farms participated together with one additional farm. In both years the farmers were asked to complete a form containing questions about the management of the cattle on the farm, including questions concerning deworming practices. In the second year the form was more detailed, and it then also contained questions about utilization of the pastures and figures on the milk production. Pepsinogen concentrations and O. ostertagi antibody levels were measured in sera following ringtesting and according to standard operating procedures (SOP). In each run a set of standard samples was included to validate the test results. Also, the milk samples were analysed in a similar fashion using the $O$. ostertagi-ELISA from SVANOVA biotechnology, Uppsala, Sweden.

It was found that the majority of the herds were stabled in September to October. However, the housing dates varied a lot. Notably, some farmers housed their animals in late December. In both years, most farmers treated their FSG with an anthelmintic. However, a large proportion (38\%) was left untreated. The preferred anthelmintic in 2006 was the oxfenbendazole intermittent release device (Systamex Repidose ${ }^{\odot}$ ). This drug was used on $85 \%$ of the farms. No samples had a serum pepsinogen concentration that exceeded the proposed cut-off concentration of $3.5 \mathrm{U}$ tyrosin, indicative of subclinical ostertagiosis. The highest value measured was $2.9 \mathrm{U}$ tyrosin. Still, both the mean pepsinogen concentrations and serum antibody levels against $O$. ostertagi were on an average higher for calves from the untreated herds. However, there was only a weak positive correlation between the Ostertagia- antibody levels and pepsinogen concentrations when the results of the same serum samples was compared $(\mathrm{R}=0.34)$. Furthermore, there was no association between the Ostertagia-antibody levels in bulk tank milk and in sera from the FSG from the same herd. On the other hand, there was a good agreement between OD values obtained in different years, and in particular for the milk samples.

A retrospective study was also carried out to assess the possibility of using daily weight gain in first-season grazing cattle (FSG) as a marker for treatment decisions to prevent parasite-induced losses caused by gastrointestinal (GI) nematodes. Data were combined from three independent grazing trials, each of which was repeated over 2-3 years, in order to investigate the influences of parasites on the performance of FSG cattle subjected to different levels of parasite control. ROC analyses showed that anthelmintic treatment of animals with a daily weight gain (Dwgt) of $<0.75 \mathrm{~kg} /$ day by mid-season had a sensitivity of $\sim 70 \%$ and a specificity of $\sim 50 \%$. It thus seems feasible to base a targeted selective treatment for FSG cattle on Dwgt recorded approximately 4-8 weeks after turn-out, provided that it is accepted that some animals will be dewormed without need. However, these data were pooled from a number of disparate trials, so that these sources of variation were included in the experiment but their individual effects cannot be determined. The next stage is to validate the conclusions in a controlled field trial.

\section{Acknowledegements}

The financial support of PARASOL (Parasite Solutions), EU thematic priority areas Food Quality and Safety (FP6, FOOD-2004-T5.4.6.6), and FORMAS (2202007-1616) and the linguistic revision by David Morrison is gratefully acknowledged.

\section{Published: 13 October 2010}

\section{References}

1. Anon: Jordbruksstatistisk årsbok. 2008, (tab 10.2).

2. DFS: Djurskyddsmyndighetens författningssamling. Saknr L 2007, 100D

3. Dimander SO, Höglund J, Uggla A, Spörndly E, Waller PJ: The impact of internal parasites on the productivity of young cattle organically reared on semi-natural pastures in Sweden. Veterinary Parasitology 2000, 90:271-284.

4. Dimander SO, Höglund J, Spörndly E, Waller PJ: Evaluation of gastrointestinal nematode parasite control strategies for first-season grazing cattle in Sweden. Veterinary Parasitology 2003, 111:193-209.

5. Höglund J, Svensson C, Hessle A: A field survey on the status of internal parasites in calves on organic dairy farms in southwestern Sweden. Veterinary Parasitology 2001, 99:1-17.

6. Höglund J, Viring S, Törnqvist M: Seroprevalence of Dictyocaulus viviparus in first grazing season calves in Sweden. Veterinary Parasitology 2004, 125:343-352. 
7. Höglund J, Törnqvist M, Rydzik A, Ljungström B-L: Best use of doramectin in first season grazing cattle in Sweden. Svensk Veterinärtidning 2008, 4:11-18, (In Swedish with an English summary).

8. Larsson A, Dimander SO, Rydzik A, Uggla A, Waller PJ, Höglund J: A 3-year field evaluation of pasture rotation and supplementary feeding to control parasite infection in first-season grazing cattle-Effects on animal performance. Veterinary Parasitology 2006, 142:197-206.

9. KRAV: Standards for organic certified production. Heath and medical care 2007, 5.4:50-52.

10. Corwin RM: Economics of gastrointestinal parasitism of cattle. Vet Parasitol 2007, 72:451-457.

11. Eysker M, Ploeger HW: Value of present diagnostic methods for gastrointestinal nematode infections in ruminants. Parasitology 2000, 120: S109-119.

12. Dorny P, Shaw DJ, Vercruysse J: The determination at housing of exposure to gastrointestinal nematode infections in first-grazing season calves. Veterinary Parasitology 1999, 80:325-340.

13. Ploeger HW, Kloosterman A, Borgsteede FH: Effect of anthelmintic treatment of second-year cattle on growth performance during winter housing and first lactation yield. Veterinary Parasitology 1990, 36:311-323.

14. Ploeger HW, Kloosterman A, Bargeman G, von Wuijckhuise L, van den Brink R: Milk yield increase after anthelmintic treatment of dairy cattle related to some parameters estimating helminth infection. Veterinary Parasitology 1990, 35:103-116.

15. Ploeger HW, Kloosterman A, Rietveld FW, Berghen P, Hildersson H, Hollanders W: Quantitative estimation of the level of exposure to gastrointestinal nematode infections in first-year calves. Veterinary Parasitology 1994, 55:287-315.

16. Sanchez J, Dohoo IR, Markham F, Leslie K, Conboy G: Evaluation of the repeatability of a crude adult indirect Ostertagia ostertagi ELISA and methods of expressing test results. Veterinary Parasitology 2002, 109:75-90.

doi:10.1186/1751-0147-52-S1-S25

Cite this article as: Höglund: Parasite surveillance and novel use of anthelmintics in cattle. Acta Veterinaria Scandinavica 2010 52(Suppl 1):S25.

\section{Submit your next manuscript to BioMed Central and take full advantage of:}

- Convenient online submission

- Thorough peer review

- No space constraints or color figure charges

- Immediate publication on acceptance

- Inclusion in PubMed, CAS, Scopus and Google Scholar

- Research which is freely available for redistribution

Submit your manuscript at www.biomedcentral.com/submit
Biomed Central 